\title{
Similarity of temperature and concentration field in Poiseuille-Benard channel flow
}

\author{
Jakub Devera ${ }^{1, *}$, Tomáš Hyhlík ${ }^{1}$, and Radomír Kalinay ${ }^{1}$ \\ ${ }^{1}$ CTU in Prague, FME, Department of Fluid Dynamics and Thermodynamics, Technická 4, 16607 Prague
}

\begin{abstract}
A flow over hot water film in horizontal channel (Poiseuille-Benard flow) is studied experimentally and by means of CFD. Averaged temperature and concentration fields were measured in central transverse plane using RTD and capacitive humidity probe for different $R i=G r / R e^{2}$. A similarity of thermal and concentration field is discussed and the influence of thermal and humidity field by radiative heat transfer is investigated since it has a considerable effect. Same cases are modeled by CFD in commercial code Star-CCM+. Simulated thermal and concentration fields shows similar character as those from measurements when radiative heat transfer mode is considered.
\end{abstract}

\section{Introduction}

The heat and mass transfer analogy is often used in many industrial calculations (evaporation rate from liquid films and droplets, cooling towers [1], building simulations [2], etc.) to convert heat transfer coefficient into mass transfer coefficient. However, the applicability of the analogy is valid for strict range of conditions. Boukadida and Nasrallah [3] concluded that the radiative transfer mode breaks the heat and mass transfer analogy and the ambient temperature and relative humidity are the main parameters which influence the accuracy of the analogy. Natural convective heat transfer has usually higher temperature difference between hot surface and free stream than during forced convection and therefore the role of radiation is more significant. The analogy exists between heat and mass transfer coefficient as same as between thermal and concentration field.

In previous work of authors [4] radiation influence of mixed convection flow was investigated. By means of experimental and numerical analysis of thermal field of the channel flow (Poiseuille-Benard flow over hot fluid film), a significant influence of radiation was observed with relatively small $\Delta T\left(\Delta T \approx 30^{\circ} \mathrm{C}\right.$ and with free stream temperature $\approx 20^{\circ} \mathrm{C}$ ). For deeper understanding, additional measurement of humidity field in the channel was prepared. The analogy's validity is assessed based on similarity of thermal and concentration field. Measured concentration field is also compared with numerical simulation carried out in commercial code Star-CCM+.

The aim of the present study is discuss how radiation influences the thermal and humidity field (and its similarity) in mixed convection flow above a hot horizontal film. The thermal and humidity field is measured in cen-

*e-mail: jakub.devera@fs.cvut.cz tral streamwise plane and compared with numerical simulation.

\section{Poiseuille-Benard channel flow}

Mixed convection flow in a horizontal rectangular channel of height $\mathrm{H}$, width $\mathrm{B}(H=B)$ and length $\mathrm{L}$ is considered (fig. 1). The side walls of the channel are insulated. An entrance region is followed by the liquid film kept at a constant and uniform temperature $T_{h}$ (in this text is further used $T_{\text {film }}$ denoting the film temperature), higher than the inlet temperature $T_{0}$ (also denoted as $T_{\infty}$ ). This type of flow is called Poiseuille-Benard channel flow.

The Poiseuille-Benard flow is very often used for validation of the numerical code (typical conditions: $R e=10$, $P e=20 / 3$ and $R a=10^{4}$ ). Its open boundary conditions complicates the solution due to the interaction of the convective rolls with the exit boundaries and the resulting flow is a severe test for numerical codes in computational fluid mechanics [5]. However this type of flow can be found in many engineering applications: heat exchangers, HVAC systems or in CVD reactors.

Both free and forced convection participate in heat and mass transfer from the liquid film. Hot liquid film induces

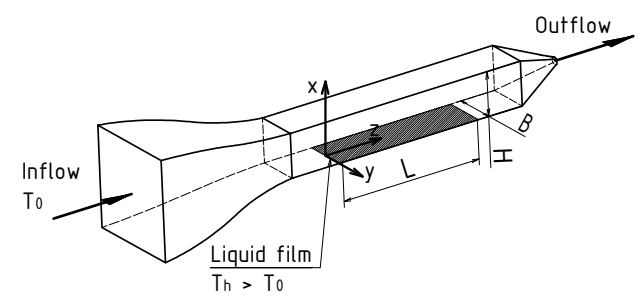

Fig. 1. Schematic of the channel with used coordinate system 
buoyancy driven secondary transverse flow, which alters the velocity field and temperature field. Mixed convection can be characterized by Richardson number [6]

$$
R i=\frac{G r}{R e^{2}}
$$

where $G r$ is Grashof number and $R e$ is Reynolds number. Richardson number characterizes the ratio of buoyancy and inertia forces. If $R i>>1$, natural convection is the main convective mode and forced convection can be neglected and vice versa for $R i<<1$. If $R i \approx 1$, contribution from buoyancy and inertia forces are in the same relative order of magnitude.

\section{Experimental apparatus}

Experimental measurements were conducted in low speed aerodynamic tunnel with hot water film at the bottom side of the test section. The test section has square cross section with $D_{h}=H=B=300 \mathrm{~mm}$. The length $L$ of the film is $1000 \mathrm{~mm}$. The tunnel was designed for measurements of the evaporation rate from the water film and mass transfer coefficient. Obtained results were used for validation of CFD model focused on evaporation from water film to moist air stream [7]. The tunnel allows to set velocities in range of $v=(0 \div 0.4) \mathrm{m} / \mathrm{s}$ and water film temperature difference $\Delta T=T_{\text {film }}-T_{\infty}=(0 \div 40)^{\circ} \mathrm{C}$. The test section is made from plexiglass and the walls are insulated by $25 \mathrm{~mm}$ mirelon plates. Water film lays at aluminum plate.

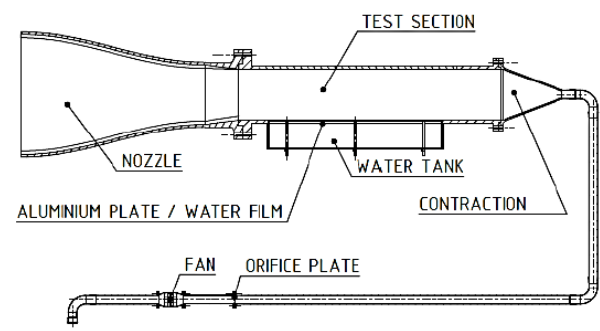

Fig. 2. Schematic of the experimental test rig

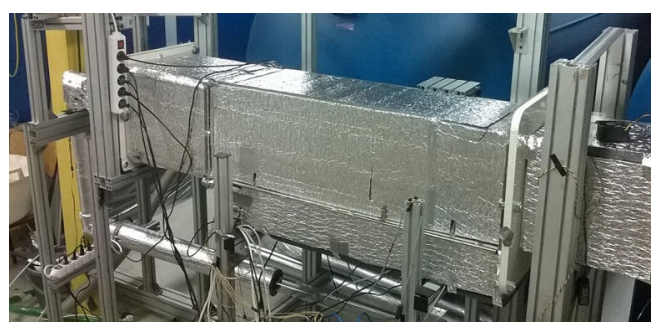

Fig. 3. Photograph of the test section

\subsection{Test rig's conditions monitoring}

The aluminium plate is equipped with 18 temperature sensors (digital thermometers Ds18b20) for measurement plate's temperature and uniformity. The maximal deviation of the local temperature from the mean value is less than $1^{\circ} \mathrm{C}$. The air mass flow rate is measured by orifice plate. Differential pressure transducer Setra 265 with range \pm 0.5 inch $w c \approx \pm 125 \mathrm{~Pa}$ and \pm 2.5 inch $w c \approx \pm 623 \mathrm{~Pa}$ (for higher flow rates) are used for measurement of the orifice pressure difference. The mass flow rate is evaluated according to standard CSN EN ISO 5176-2. Outlet temperature and specific humidity is measured by psychrometers made from two sheathed RTD probes (PT1000). Inlet temperature and relative/specific humidity is measured by capacitive HygroSmart HS3 Probe (temperature is measured by RTD PT1000 and humidity by Michell H8000). Digital signal output via Modbus RTU is used.

\subsection{Humidity and thermal field measurement}

In previous measurements $[4,8]$ focused on thermal fields, the thermal field was measured with 10 thermocouples, type $\mathrm{K}$. Whole $1000 \mathrm{~mm}$ region above the film was traversed by the probe stand, also $300 \mathrm{~mm}$ in front of and $100 \mathrm{~mm}$ behind the test section is included, in total 15 horizontal positions (horizontal distance between each position was $100 \mathrm{~mm}$ ) with $31 \mathrm{~mm}$ vertical distance between thermocouples. The field was reconstructed from 150 points. Comparison of the measured fields with CFD is in [4] where is also discussed significant effect of the thermal radiation.

Combined humidity and thermal field measurement is realized with Vaisala HMT313 probe with $4-20 m A$ output for relative humidity and temperature. Probe was calibrated six months before the measurements ( 5 point calibration, ISO9001 compliant). The output current is measured by NI module 9203 combined with NI cDAQ 9188. Data are gathered by LabVIEW and postprocessing is done in Matlab. Probe was mounted to a traversing stand. 11 horizontal positions were traversed: whole space from the start to the end of the water film with distance $100 \mathrm{~mm}$. 5 vertical positions were chosen: $x=[40,100,150,210,270] \mathrm{mm}$. The field is reconstructed from 55 points. In each point is waited from thermal and humidity stability. After the stability is reached, humidity/temperature is measured for $240 s$ with $2 s$ sampling time. Data are averaged therefore only average thermal and humidity field is obtained.

\section{Numerical simulation}

For numerical simulations, commercial CFD code Star$\mathrm{CCM}+$ is used. The geometry of the experimental setup was reduced to cover only the nozzle, test section and contraction and part of outlet pipe, see fig. 1 and fig. 4. The multi-component gas phase is governed by the incompressible Navier-Stokes equations. To deal with buoyancy forces, Boussinesq approximation is employed [9]. Following assumptions are taken to simplified the simulation case: the flow in the channel is considered as steady (unstationary behavior is averaged with RANS approach). The water film is assumed to be thin and a saturated layer 
of moist air above the fluid film is assumed. Therefore it is possible to treat the film as a boundary condition and prescribe water vapor mass fraction [9]

$$
\omega_{v}=\frac{M_{v}}{M_{a}} \frac{p_{v}^{\prime \prime}\left(T_{f i l m}\right)}{p_{a t m}-\left(1-\frac{M_{v}}{M_{a}}\right) p_{v}^{\prime \prime}\left(T_{\text {film }}\right)}
$$

where $M_{a}=28.97 \mathrm{~g} / \mathrm{mol}$ and $M_{v}=18.02 \mathrm{~g} / \mathrm{mol}$ are the values of molar mass of air and water vapour, $p_{a t m}$ is atmospheric pressure and $p_{v}^{\prime \prime}$ is saturation pressure of water vapor at temperature of the water film. Turbulence is modeled by Realizable $k-\epsilon$ Two-Layer model together with Buoyancy Driven Two-Layer Type model.

\subsection{Radiative heat transfer}

The simulations are run in two variants: with and without radiation. In the majority part of the fluid domain, the moist air is not saturated and it does not participate in radiative heat transfer, therefore radiation Surface-toSurface model is used. Radiation properties of surfaces are considered same for all wavelengths, the Gray Thermal Radiation model is used.

\subsection{Boundary conditions}

The water film area is defined as a Dirichlet boundary condition employing eq. (2). The water vapor mass flux is evaluated with inhouse STAR-CCM+ function Boundary Species Flux. The function is also used as species source in the area of the fluid film. Although the test rig is insulated, heat dissipation through the walls is still considered and based on the experimental data, convection boundary condition is used (heat transfer coefficient is prescribed on the walls).

\section{Results and interpretation}

The role of natural and forced convection is assessed based on $R i$ number as was mentioned earlier in the text. $R i$ is calculated from $R e$ number and $G r$ number. In both numbers is characteristic length. Two length are assumed: dimensionless numbers based on hydraulic diameter are denoted with subscript $D$ and numbers based on length of water film are denoted with subscript $L$. Re is calculated using mean velocity in the test section determined from the mass flow rate.

Two cases are presented in this paper:

1. $\Delta T=T_{\text {film }}-T_{\infty}=30^{\circ} \mathrm{C}, T_{\infty}=26.4^{\circ} \mathrm{C}$

2. $\Delta T=T_{\text {film }}-T_{\infty}=20^{\circ} \mathrm{C}, T_{\infty}=25.3^{\circ} \mathrm{C}$
Corresponding dimensionless numbers are summarized in tab. 1 together with Prandtl and Schmidt number.

\subsection{Processing of the results}

Whole transverse plane from numerical simulation (case 1 - with radiation) is shown in fig. 4. Experimentally investigated section is in the rectangle. Both, thermal and humidity field from measurement and simulation are normalized according

$$
T^{+}=\frac{T-T_{\infty}}{T_{f i l m}-T_{\infty}}
$$

and

$$
x^{+}=\frac{x-x_{\infty}}{x_{f i l m}-x_{\infty}}
$$

where $x$ is specific humidity (humidity ratio), $x_{f i l m}$ is specific humidity of the saturated moist air in the thin layer above the water film. Normalized $T^{+}$and $x^{+}$are then mapped to range $\langle 0,1\rangle-$ see fig. 5 and 7 . The purpose of the normalization (eq. (3) and (4)) is for data processing and for comparison of the overall structure of the field. The fields can not be exactly similar due to inequality of Prandtl and Schmidt number (1) and due to radiative heat transfer.

Fields from simulation are interpolated to the same grid as it is used in experiment to obtain comparable results. Absolute differences between simulated and measured temperature and humidity fields are also plotted see fig. 6 and 8 .

\subsection{Discussion}

\subsubsection{Structure of the thermal and humidity field}

From values written in tab. 1 can be seen that natural convection is dominant convective mode and is the main driving force for the heat and mass transfer. Buoyancy forces induced secondary flow (Benard convection) and alters forced Poiseuille flow - see fig. 4. Below the top surface specific humidity reach $x \approx 22 g_{v} / k g_{d a}$ even in the region of the nozzle which is two times higher value than the inlet specific humidity. That is caused due to strong reverse flow along the top desk. The flow reversal makes the fluid in the upper region hotter than that below due to the convective heat transfer from the downstream fluid [10]. Described behaviour results in one large convective roll in the channel. At the inlet, used CFD code could not resolve the interaction of backflow with inlet air stream. That leads to deformation of the air stream in the region of the nozzle.

\begin{tabular}{|c|c|c|c|c|c|c|c|c|c|c|c|c|c|c|c|}
\hline \multicolumn{1}{|c|}{ Case 1 } & \multicolumn{1}{c|}{ Case 2 } \\
\hline$R e_{D}$ & $R e_{L}$ & $G r_{D}$ & $G r_{L}$ & $R i_{D}$ & $R i_{L}$ & $P r$ & $S c$ & $R e_{D}$ & $R e_{L}$ & $G r_{D}$ & $G r_{L}$ & $R i_{D}$ & $R i_{L}$ & $P r$ & $S c$ \\
\hline 2025 & 6750 & $9.960 \mathrm{e} 7$ & $3.689 \mathrm{e} 9$ & 24.3 & 81.0 & 0.761 & 0.521 & 2008 & 6693 & $6.993 \mathrm{e} 7$ & $2.590 \mathrm{e} 9$ & 17.4 & 57.8 & 0.751 & 0.550 \\
\hline
\end{tabular}

Table 1. Evaluated dimensionless numbers significant for mixed convection heat and mass transfer for both investigated cases 


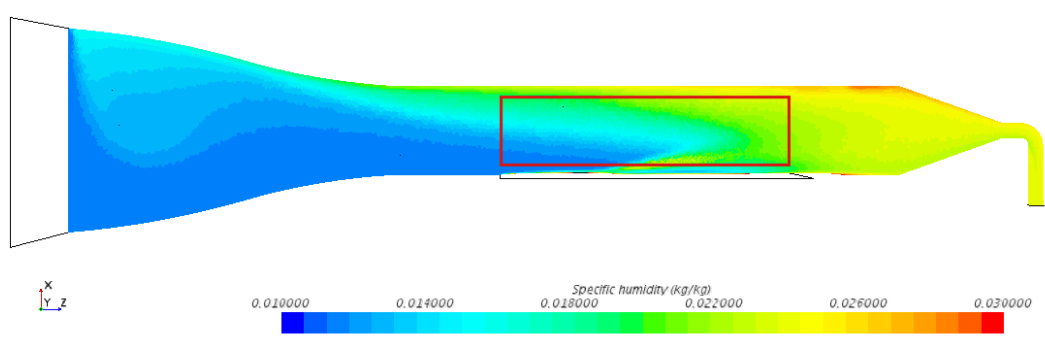

Fig. 4. Simulated specific humidity (Case 1) field in streamwise central plane showing the influence of reverse flow along the top surface of the channel. Red rectangle region is investigated also experimentally (see online version for colors)

\subsubsection{Radiation influence}

For each case, 3 normalized thermal and 3 normalized concentration fields are obtained: from measurement, from CFD analysis with no radiative heat transfer assumed and with radiation (fig. 5 and fig. 7). Absolute differences of measurement and simulations are in fig. 6 and fig. 8.

Obtained thermal and concentration field from experiment (fig. 5a-b, fig. 7a-b, ) has structure discussed in the section above. The structure of the humidity and temperature field is similar due to close values of $S c$ and $P r$ number. The similarity is broken mainly top fluid region. Top surface is heated by the radiation emitted from water film and the top desk heats the fluid subsequently. This is not observed in the concentration field, where the maximum specific humidity is at the end of water film and further in the outlet section of the test rig (fig. 4).

In the case where radiative heat transfer is not assumed (fig. 5c-d and fig. 7c-d,), the fluid is significantly colder, but the flow reversal along the top surface is observed and overall structure is the same. In case 2, the backflow is very weak. Absolute temperature difference of simulation and measurement is ranging for both cases 1 from $2^{\circ} \mathrm{C}$ to $4^{\circ} \mathrm{C}$ in almost entire region (fig. 6a and fig. 8a).

When Surface to surface radiation model is included in the simulation (fig. 5e-f, fig. 7e-f,), the fluid temperature is predicted more accurately, for both cases the absolute temperature differences is ranging from 0 to $2^{\circ} \mathrm{C}$ maximally. The influence of radiation is therefore considerable and accurate fluid temperature prediction is achieved (fig. $6 \mathrm{c}$ and fig. 8c).

Concentration field is for case 1 is in both simulation runs (with and without radiation) predicted accurately except some local spots, difference in specific humidity is ranging from 0 to $2 g_{v p} / k g_{d a}$ on average (fig. $6 \mathrm{~b}$ and fig. 6d). Larger differences are in case $2\left(\Delta T=20^{\circ} \mathrm{C}\right)$. The buoyancy forces creates weak backflow if no radiation is assumed. Due to that, bigger discrepancies between experiment and simulation are in the upper region (fig. 8b). When radiation is assumed, the concentration field is predicted accurately, difference in specific humidity max 1.5 $g_{v p} / k g_{d a}$.

\section{Conclusion}

Similarity of thermal and concentration field in mixed convection flow is studied by means of experiment and CFD. Higher $R i$ numbers indicates dominant role of natural convection. Concentration and thermal field has similar structure, main differences are below top surface of the channel which is exposed to radiation from the water film. This behavior is observed in both tested cases $\left(\Delta T=[20,30]^{\circ} C\right)$. Each case was compared to CFD simulation and more accurate results are when radiative heat transfer is assumed. In the case $2\left(\Delta T=20^{\circ} \mathrm{C}\right)$, the radiation is even more significant since it helps to induce the backflow along the top surface. Radiation has therefore large impact in mixed and natural convection flows on fluid temperature and should be assumed during the simulations. Radiation also breaks the similarity between thermal and concentration fields in regions near surfaces that are exposed to radiation.

This work was supported by the Grant Agency of the Czech Technical University in Prague, grant No. SGS18/124/OHK2/2T/12.

\section{References}

[1] J.C. Kloppers, D.G. Kröger, Int. J. Therm. Sci. 44, 879 (2005)

[2] H.-J. Steeman, A. Janssens, M. De Paepe, Int. J. Heat Mass Transfer 52, 1431 (2009)

[3] N. Boukadida, S.B. Nasrallah, Int. J. Therm. Sci. 40, 67 (2001)

[4] J. Devera, T. Hyhlík, AIP Conf. Proc. 2000, 020004 (2018)

[5] H. Abbassi, M. Magherbi, A.B. Brahim, Int. J. Therm. Sci. 42, 1081 (2003)

[6] F.P. Incropera, T. L. Bergman, Fundamentals of heat and mass transfer, 7th ed, Wiley (2011)

[7] S. Kastrati, T. Hyhlík, R. Kalinay, Topical Problems Fluid Mech. 167 (2018)

[8] J. Devera, T. Hyhlík, EPJ Web Conf. 180, 02019 (2018)

[9] P. Sosnowski, A. Petronio, V. Armenio, Int. J. Heat Mass Transfer 66, 382 (2013)

[10] D.K. Choi, D.H. Choi, Int. J. Heat Mass Transfer 37, 1899 (1994) 
a)

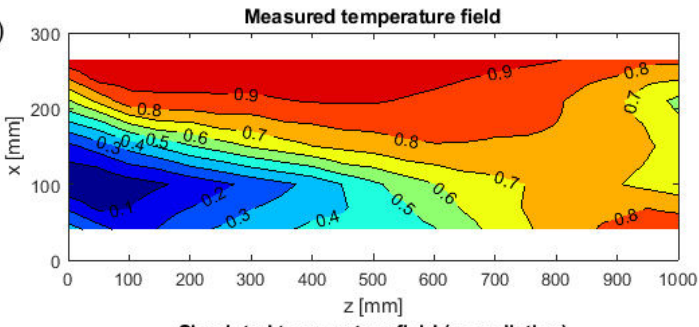

c)

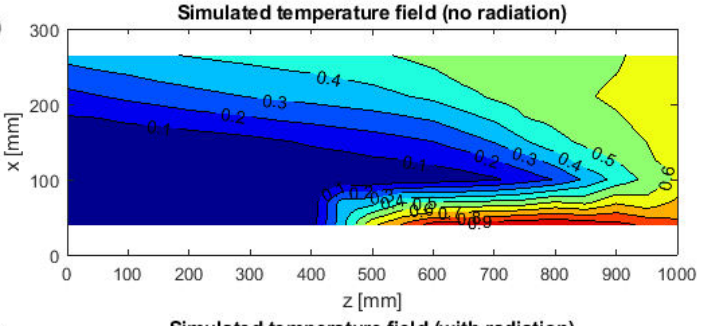

e)

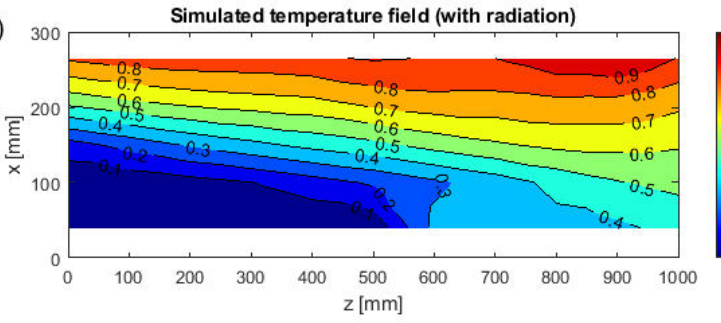

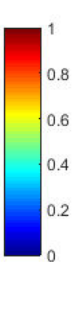
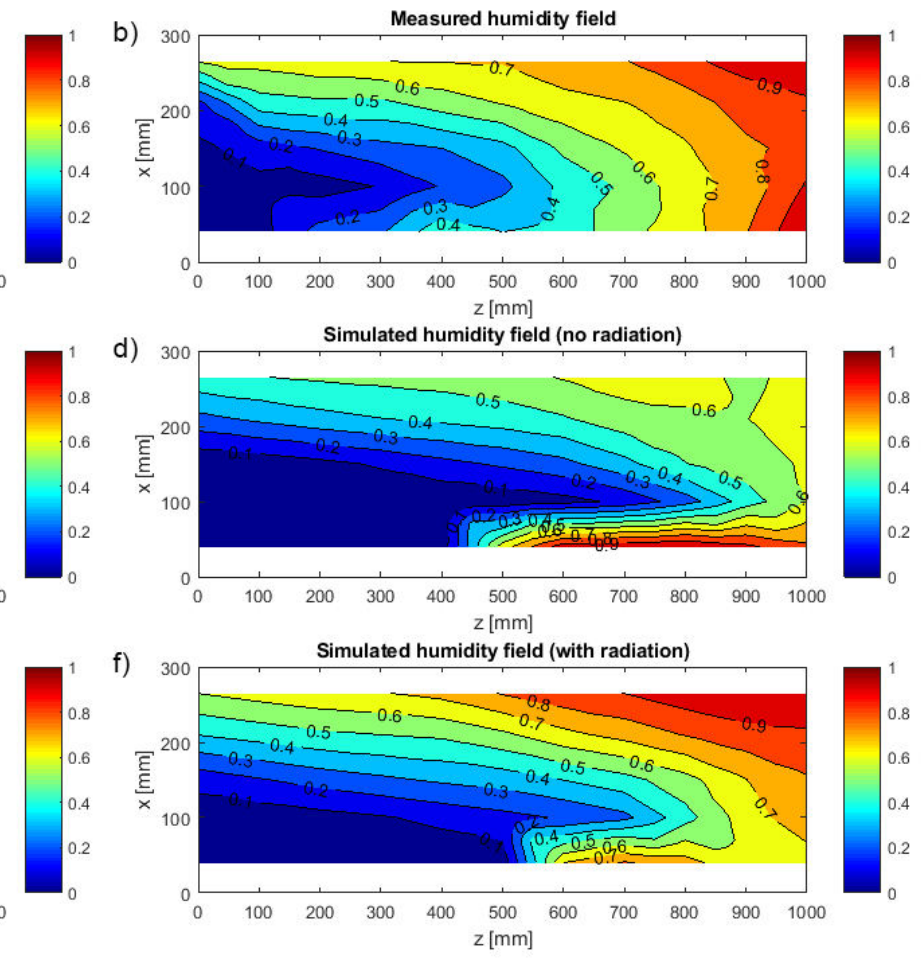

Fig. 5. Case $1\left(\Delta T=30^{\circ} C\right)$ : Normalized thermal (left) and concentration fields (right) - a,b: experimentally measured; c,d - CFD simulation without radiation; e,f - CFD with radiation (see online version for colors)

a)

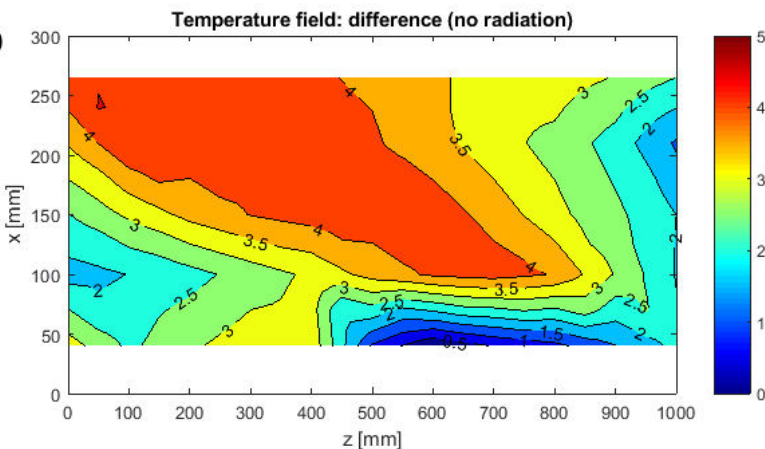

c)

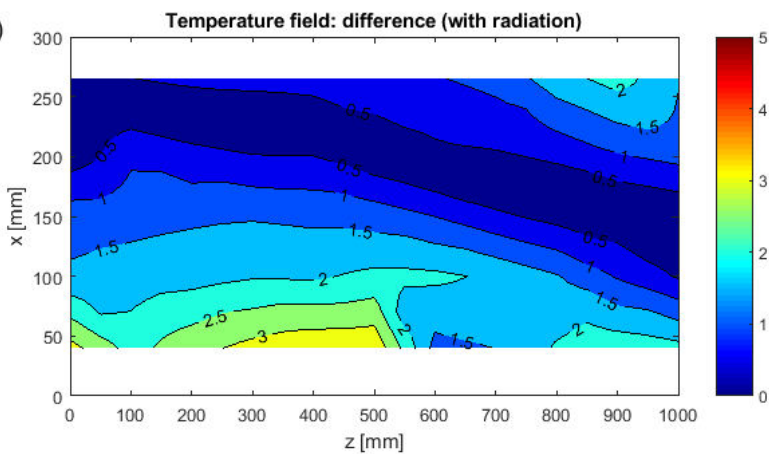

b)

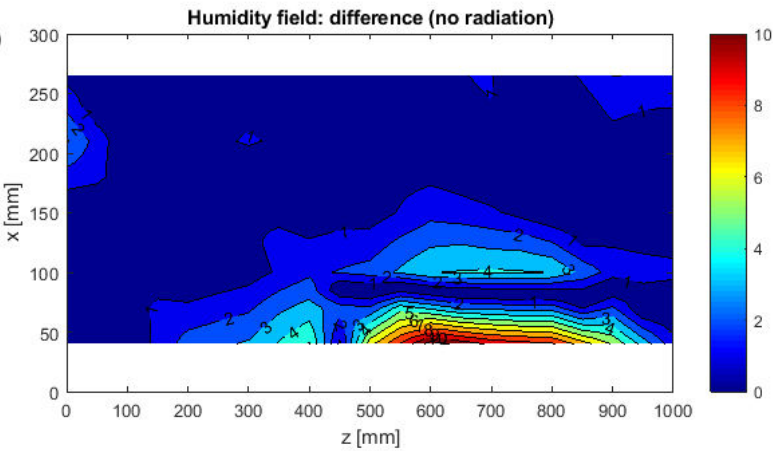

d)

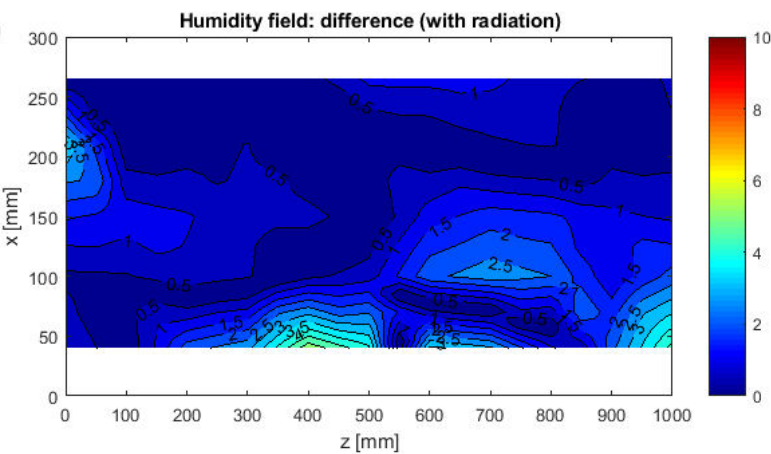

Fig. 6. Case $1\left(\Delta T=30^{\circ} \mathrm{C}\right)$ : Comparison of experiment and CFD - measured field is subtracted from simulated field (absolute differences are plotted), temperature differences are in ${ }^{\circ} \mathrm{C}(\mathrm{a}, \mathrm{c})$; specific humidity differences are in $g_{v p} / k g_{d a}(\mathrm{~b}, \mathrm{~d})$ 
a)

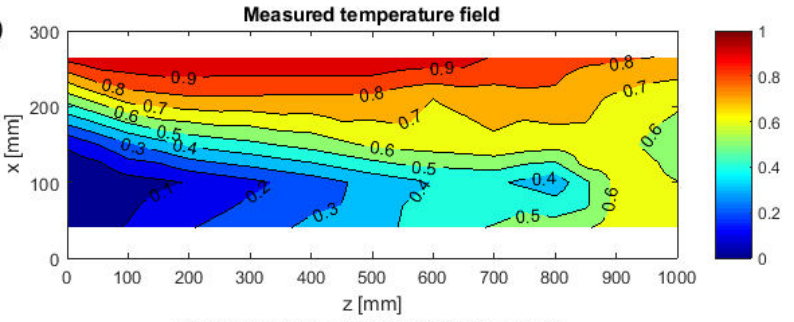

c)

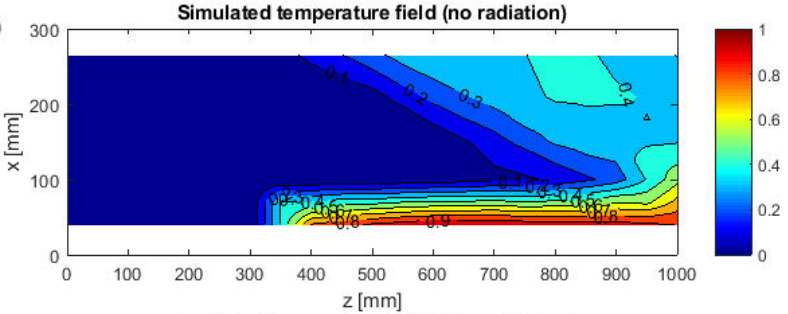

e)

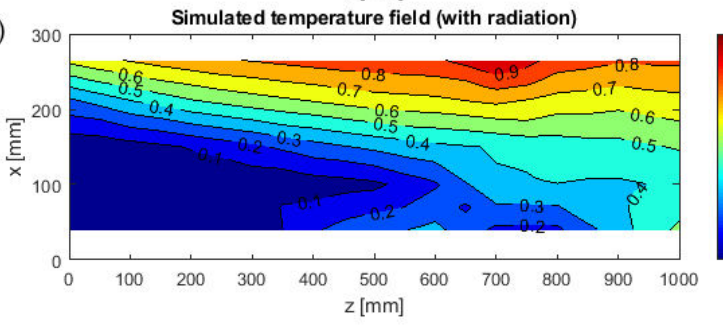

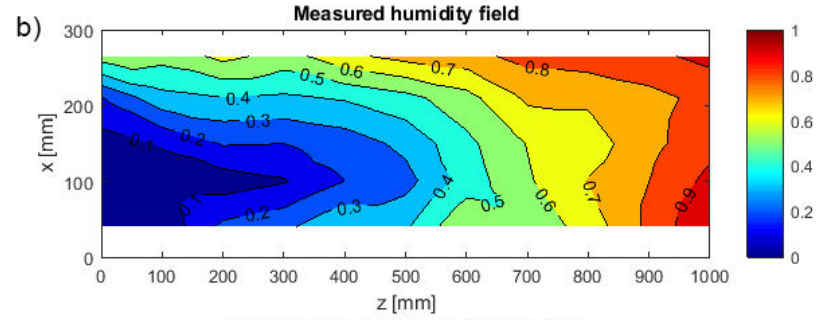
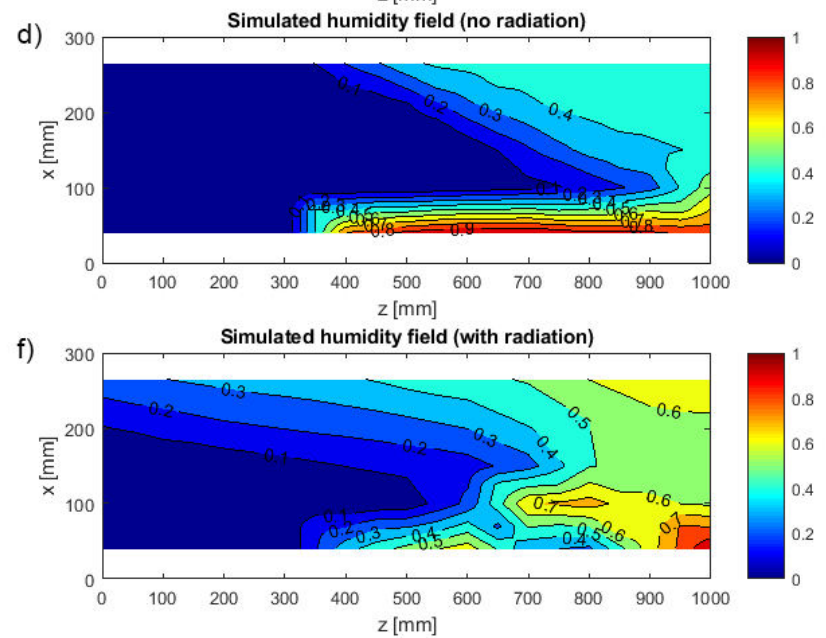

Fig. 7. Case $2\left(\Delta T=20^{\circ} \mathrm{C}\right)$ : Normalized thermal (left) and concentration fields (right) - a,b: experimentally measured; c,d - CFD simulation without radiation; e,f - CFD with radiation (see online version for colors)

a)

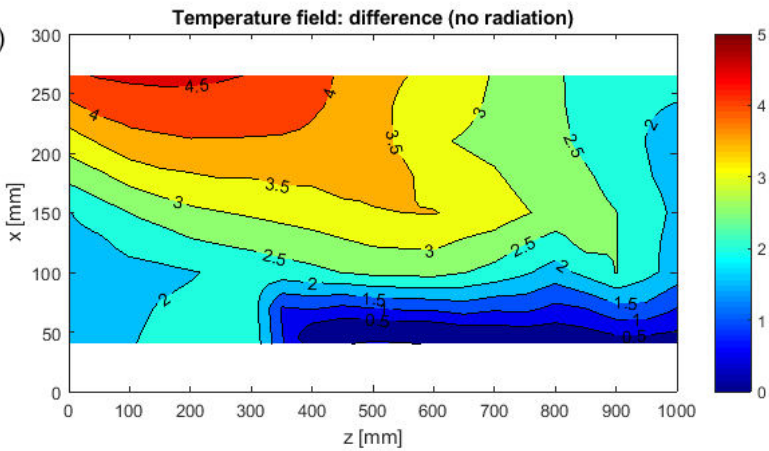

c)

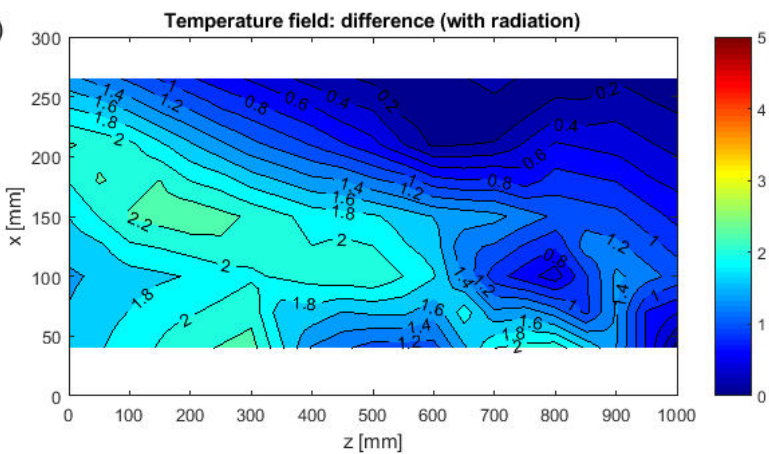

b)

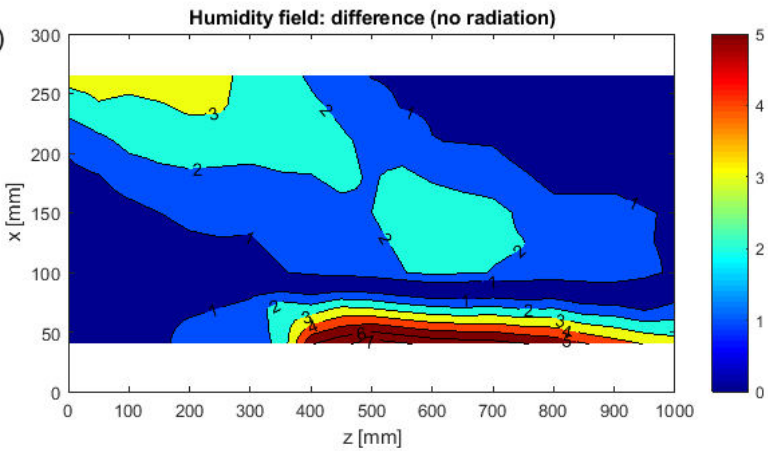

d)

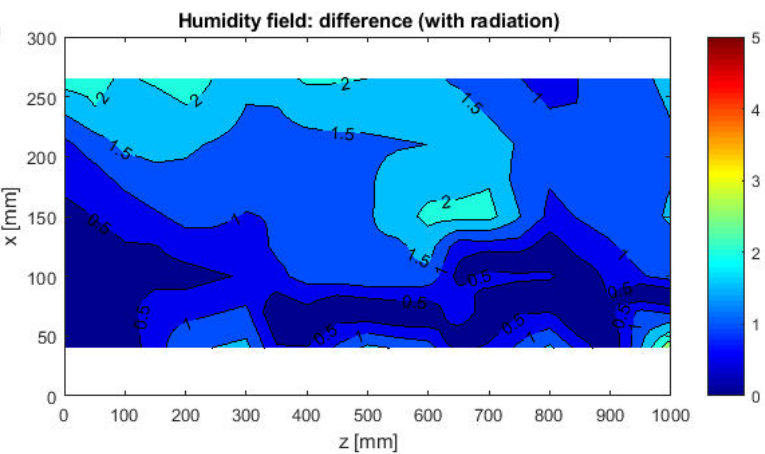

Fig. 8. Case $2\left(\Delta T=20^{\circ} \mathrm{C}\right)$ : Comparison of experiment and CFD - measured field is subtracted from simulated field (absolute differences are plotted), temperature differences are in ${ }^{\circ} \mathrm{C}(\mathrm{a}, \mathrm{c})$; specific humidity differences are in $g_{v p} / k g_{d a}(\mathrm{~b}, \mathrm{~d})$ 